\title{
BMJ Open Supervised pharmacy student-led medication review in primary care for patients with type 2 diabetes: a randomised controlled pilot study
}

\author{
R P Adams, ${ }^{1}$ G Barton, ${ }^{2}$ D Bhattacharya, ${ }^{1}$ P F Grassby, ${ }^{3}$ R Holland, ${ }^{4}$ A Howe,${ }^{4}$ \\ N Norris, ${ }^{5}$ L Shepstone, ${ }^{2}$ D J Wright ${ }^{1}$
}

To cite: Adams RP, Barton G, Bhattacharya $\mathrm{D}$, et al. Supervised pharmacy student-led medication review in primary care for patients with type 2 diabetes: a randomised controlled pilot study. BMJ Open 2015;5: e009246. doi:10.1136/ bmjopen-2015-009246

- Prepublication history for this paper is available online. To view these files please visit the journal online (http://dx.doi.org/10.1136/ bmjopen-2015-009246)

Received 2 July 2015 Revised 8 October 2015 Accepted 16 October 2015

CrossMark

For numbered affiliations see end of article.

Correspondence to

DJ Wright;

d.j.wright@uea.ac.uk

\section{ABSTRACT}

Objective: To pilot and feasibility-test supervised final year undergraduate pharmacy student-led medication reviews for patients with diabetes to enable definitive trial design.

Method: Third year pharmacy students were recruited from one UK School of Pharmacy and trained to review patient's medical records and provide face-to-face consultations under supervision while situated within the patient's medical practice. Patients with type 2 diabetes were recruited by postal invitation letter from their medical practice and randomised via automated system to intervention or usual care. Diabetes-related clinical data, quality of life, patient reported beliefs, adherence and satisfaction with medicines information were collected with validated tools at baseline and 6 months postintervention. The process for collecting resource utilisation data was tested. Stakeholder meetings were held before and after intervention to develop study design and learn from its implementation. Recruitment and attrition rates were determined plus the quality of the outcome data. Power calculations for a definitive trial were performed on the different outcome measures to identify the most appropriate primary outcome measure.

Results: 792 patients were identified as eligible from five medical practices. $133(16.8 \%)$ were recruited and randomised to control $(n=66)$ or usual care $(n=67) .32$ students provided the complete intervention to 58 patients. Initial data analysis showed potential for impact in the right direction for some outcomes measured including glycated haemoglobin, quality of life and patient satisfaction with information about medicines. The intervention was found to be feasible and acceptable to patients. The pilot and feasibility study enabled the design of a future full randomised controlled trial.

Conclusions: Student and patient recruitment are possible. The intervention was well received and demonstrated some potential benefits. While the intervention was relatively inexpensive and provided an experiential learning opportunity for pharmacy students, its cost-effectiveness remains to be determined.

Trial registration number: ISRCTN26445805; Results

\section{Strengths and limitations of this study}

- The study followed recommendations published by the Medical Research Council for implementation of feasibility and pilot studies.

- The intervention was developed with significant stakeholder involvement, a range of primary outcome measures were tested for suitability and the process for collecting resource utilisation data was identified.

- Self-selection bias was found within those students who consented to participate.

- The trial was unblinded with the service providers, patients and research all aware of group allocation and intervention content.

- The large number of statistical tests carried out creates the possibility that findings could be false positives and as this was a pilot and feasibility study which, therefore, used a low power we could potentially fail to detect small to moderate sized effects.

\section{INTRODUCTION}

It is estimated that preventable harm from medicines costs the National Health Service (NHS) in England $£ 750$ million per year. ${ }^{1} \mathrm{~A}$ systematic review in 2009, based on UK research, estimated that only between $4 \%$ and $21 \%$ of patients achieved the optimum benefit from their medication. ${ }^{2}$ A systematic review of publications between 1966 and 1999 reported the prevalence of preventable drug-related admissions to hospital as $4.3 \%$. $^{3}$ Additionally, patients not taking their medicines as agreed with the prescriber has been reported to cost the UK NHS an estimated half a billion pounds a year. ${ }^{4}$ Consequently, interventions designed to reduce adverse drug events and improve patient medicinestaking behaviours are required.

Medication review (MR) has been defined as 'a structured, critical examination of a patient's medicines with the objective of 
reaching an agreement with the patient about treatment, optimising the impact of medicines, minimising the number of medication-related problems in addition to reducing waste. ${ }^{5} \mathrm{MR}$ in the UK was described as operating at four different levels, ${ }^{5}$ with the key component of level 3 medication reviews being the involvement of the patient while accessing medical records.

Pharmacist-led medication reviews have been shown to reduce costs associated with unnecessary prescribing of medication while potentially providing patient benefit. ${ }^{6}$ However, recent UK-based research utilising pharmacists to provide medication reviews found a counter-intuitive increase in hospitalisation, ${ }^{7}$ with one partial explanation being the didactic nature of the pharmacist communication. ${ }^{8}$ Effective communication skills are necessary to improve patient behaviours in terms of lifestyle $e^{10}$ and medication taking. ${ }^{11}$ Consequently, models of consultation behaviour have been developed and are commonly used within the education of healthcare professionals. ${ }^{12} 13$

While UK pharmacy graduates develop expertise in the pharmacology and therapeutics of medicines, undergraduate training currently lacks significant patient contact. This provides limited opportunities for the development of clinical and communication skills during training. ${ }^{14}$ In contrast, medical students routinely work with patients during their undergraduate training ${ }^{15}$ and undergraduate students within Schools of Dentistry and Optometry provide services to patients under the supervision of clinical tutors to improve both their clinical and communication skills. ${ }^{16} 17$

Involvement of pharmacy students in the provision of healthcare services in other countries has been reported $^{18} 19$ with very good prescriber acceptance of student recommendations. ${ }^{20}$ However, pharmacy student provision of medication review to patients in the UK, with the dual aims of demonstrating patient benefit and improving student communication and clinical skills, has not been tested. For new models of care to be adopted, it is necessary to demonstrate that they are likely to be costeffective. There is currently no evidence of this for the provision of pharmacy student-led medication review services.

Two and a half million of the UK population currently have type 2 diabetes with an estimated direct cost to the health system of $£ 8.8$ billion/annum. ${ }^{21}$ Pharmacist-led medication reviews for patients with diabetes have demonstrated significant reductions in blood pressure $^{22} 23$ and glycated haemoglobin (HbAlc), ${ }^{24} 25$ both of which are necessary to reduce long-term morbidity. ${ }^{26}$ Approximately $60 \%$ of patients are achieving the target HbA1c below $7.5 \%(59 \mathrm{mmol} / \mathrm{mol}) .{ }^{27}$ Owing to the availability of clearly defined national treatment guidelines $^{28-30}$ and increasing numbers of patients with type 2 diabetes, medication review for patients with diabetes is a health service which pharmacy students may be able to usefully provide.

A pilot and feasibility study was, therefore, undertaken in line with national guidance for the evaluation of complex interventions ${ }^{31}$ to determine recruitment and attrition rates for students and patients; describe the suitability of using student volunteers; test data collection for a future cost-effectiveness analysis; describe the potential effects of the intervention; identify the most suitable primary outcome measure; and estimate variance around this to enable a future trial to be effectively powered.

\section{METHOD}

ISRCTN No 26445805 was obtained retrospectively rather than prospectively due to misinterpretation of an National Institute for Health Research (NIHR) email stating that "NIHR Clinical Research Network (CRN) Coordinating centre had developed a process which enables automatic registration of all new NIHR Clinical Research Network Portfolio studies via the Portfolio." We did not notice that they provided details of ISRCTN registration via UKCRN Portfolio, later in the same email.

\section{Student recruitment and preparation}

All 84 third year pharmacy students from one UK school of pharmacy were invited to participate in June 2011. The intervention was timetabled to occur during the final year (fourth) of their undergraduate studies. Informed consent was obtained from students agreeing to participate. A reserve list was created and used to resolve any anticipated drop-out caused by the additional workload created by the study within the students' final year.

Standard education process already included basic training in consultation skills, data governance and observation of a primary care doctor in practice. In addition, participating 'study students' undertook four half-day training sessions comprising the following:

- Use of medical practice information systems using 'dummy' patient records;

- Revision of 'pharmaceutical care planning' using a care plan designed to enable recording of patient details and also to provide a guide to their consultations;

- A consultation skills workshop which included utilising dummy primary care patient records and training in basic behaviour change counselling;

- Two medicines-related consultations with preprepared and scripted professional role-play actor 'patients', following which individual and group feedback was provided.

All student activities connected with this trial were undertaken outside the university curriculum, with students donating their time. Student preparative training was undertaken at the University of East Anglia, apart from training in the use of computerised medical records which was provided by NHS Norfolk and Waveney.

Examination results for students (both participating and non-participating) were obtained at the end of year three (ie, shortly after recruitment) to identify potential student self-selection bias. 


\section{Medical practice and patient recruitment}

Five Norfolk-based medical practices were purposively recruited by NHS Norfolk and Waveney. The inclusion criteria were:

- Pharmacist working as a prescribing advisor within the practice;

- Using the SystmOne IT medical record system;

- Over 200 patients registered with type 2 diabetes.

Presence of a pharmacist was required to enable student supervision; the same system facilitate student training. A target number of patients was required to increase the opportunity for meeting recruitment targets.

\section{Patient recruitment}

Patients in each medical practice who met the following criteria were posted a letter from the practice asking them to participate in the study:

\section{Inclusion criteria}

Prescribed non-insulin medication for type 2 diabetes mellitus for at least 2 years to increase likelihood that therapy is stabilised.

\section{Exclusion criteria}

- Deemed unsuitable for inclusion in the trial by their medical practitioner for any reason;

- Enrolled into other clinical trials;

- Diagnosed with a terminal illness.

All recruited patients were randomised to intervention or control (standard care) using an automated randomisation system, developed and controlled by the clinical trials unit, which ensured concealed allocation. Randomisation was undertaken in blocks of four to maximise equality of group size. All researchers and clinical staff involved with generating outcome date were blind to participant allocation.

As a pilot study it was decided to test a number of potential primary outcome measures, with results enabling a decision as to which measure to use in a future study:

- HbAlc;

- Blood pressure;

- Lipid profile.

Secondary outcome measures were the effect on:

- Health-related quality of life (EQ-5D);

- Satisfaction with information about medicines (SIMS) $;^{32}$

- Medication adherence (MARS) $;^{33}$

- Patient's beliefs about medicines (The Beliefs and Medicines Questionnaire) ${ }^{34}$

- Diabetes Treatment Satisfaction Questionnaire (DTSQ). ${ }^{35}$

Level 2 medication reviews were undertaken by students between November 2011 and February 2012 while student-led patient consultations (level 3 medication review) took place between December 2011 and March 2012.

\section{Sample size justification}

As a pilot study it was not appropriate to power the study. Consequently we determined the likely precision of the study for estimating the effect of the intervention on the continuous end points by estimating the expected value of the half-width of the $95 \%$ CI around the difference in means between the intervention and control groups. Assuming 80 patients in each group and a SD of $1.5 \%$ in the primary outcome variable of HbA1c then the estimate from this pilot study of the effect of the intervention on this end point would be within $0.5 \%$ of its 'true' value. An observed difference in group means $>0.5 \%$ (eg, HbA1c 7\% compared to $7.5 \%$ ) would be statistically significant.

From each of the five practices, 32 patients were, therefore, required providing 160 in total (80 in each of intervention and control arms). It was planned that each student would be allocated two patients in the intervention arm for review and consequently 40 students were required.

\section{Baseline data}

Both intervention and control participants were posted a questionnaire comprising the secondary outcome measures, which included an additional question asking whether they used a medicines compliance aid.

The patient notes within the medical practice were investigated to obtain:

- Demographic data;

- Most recent results prior to recruitment for HbAlc, blood pressure and lipid profile;

- Medication utilisation (cost of all prescriptions issued for each patient for a baseline period of 3 months prior to intervention and 6 months postintervention;

- NHS resource utilisation calculated as cost (using standard NHS staff cost) of all NHS contact for a baseline period of 3 months prior to intervention and 6 months post-intervention in primary and secondary care.

The last two items were included to determine the feasibility of collecting data for a future cost-effectiveness analysis within a randomised controlled trial.

\section{Intervention}

At the patient's medical practice, students were randomised to work in pairs. This provided additional support and shared learning in addition to the wider clinical experience provided by access to additional patient records. Each pair, therefore, worked to undertake level 2 medication reviews for four intervention patients under the supervision of a PCT pharmacist. Students compared prescribing with national guidance ${ }^{28-30}$ and created individualised pharmaceutical care plans (PCP) on a predefined pro forma.

PCPs included demographics, allergies, special needs, lifestyle for example, diet and smoking status, relevant medical history, medication adherence, pharmacy use, current prescribed medication, over the counter, herbal 
and homeopathic preparation use and any care issues identified. After discussion and agreement with the supervising pharmacist, care issues identified were fed back on a custom-designed form, to either the patient's specialist diabetes nurse or medical practitioner who then decided on the final action.

Patients were then offered a range of flexible dates and times, to maximise participation of a meeting between each student and an individual patient.

The presence of a supervising pharmacist was ensured during all student-led medication reviews to ensure competence. The consultation (level 3 medication review) took place at the patient's medical practice and was separated by at least 2 weeks from the level 2 review to enable the doctor or nurse to rectify or question any problems identified by students, prior to the subsequent student-led consultation. As planned in the protocol, each student provided two patient consultations which had no time limit imposed on their duration.

\section{Follow-up}

Six months postintervention, a questionnaire was posted to both intervention and control participants. The

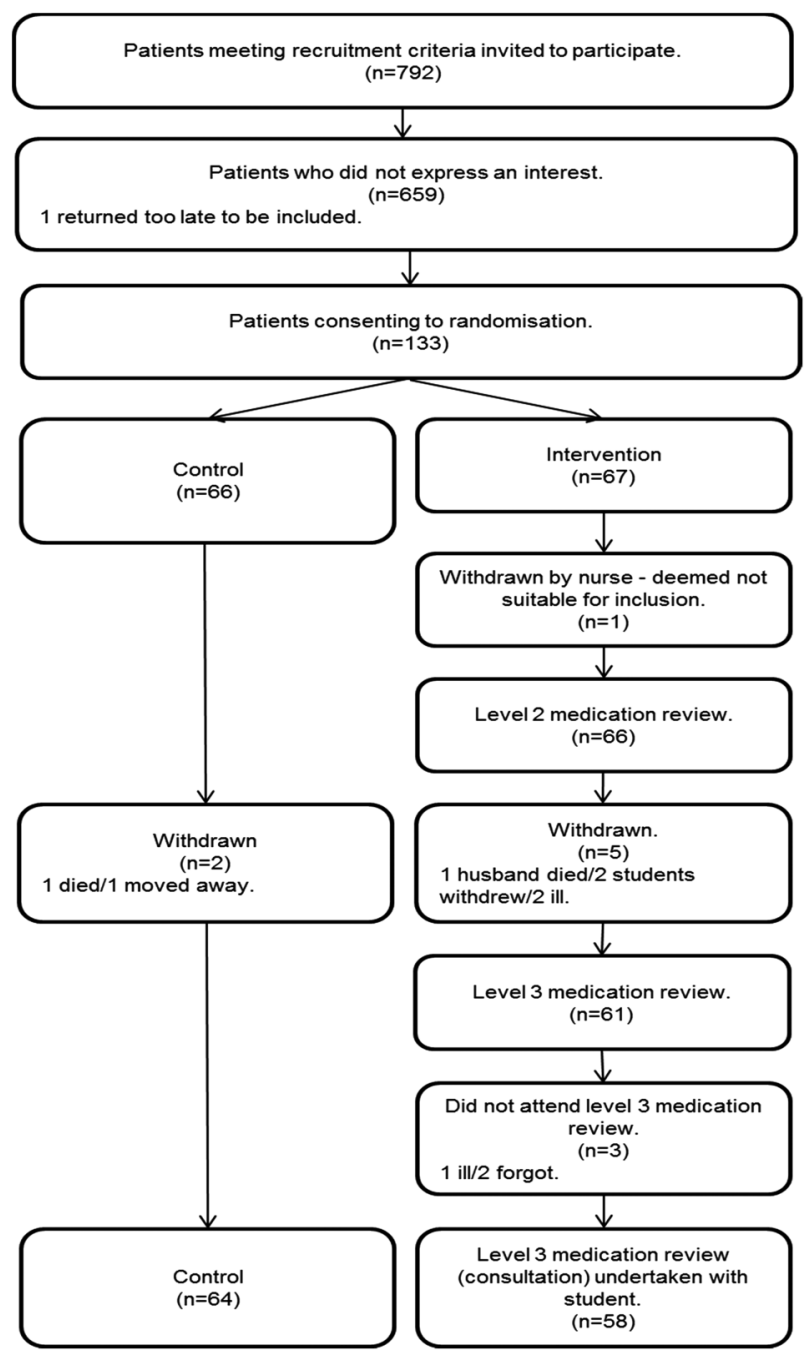

Figure 1 Consort diagram for patient recruitment. questionnaire was identical to the baseline version but with an additional question regarding frequency of community pharmacy service utilisation. Intervention participants were also asked to report any change in utilisation of community pharmacists following the student consultation to identify any change in attitude to or view of community pharmacists. The same data as baseline were collected from the medical practice, with HbAlc, blood pressure and lipid profile collected at 6 months postintervention with a cut-off point of 1 year; and medication and resource utilisation for the 6-month period postintervention.

\section{Stakeholder meetings}

Stakeholder meetings were held with patients, students, primary care pharmacists and medical practice staff both before and after the intervention. Interested individuals were recruited prior to the study's implementation to inform the design of the intervention and trial, while study participants were recruited postintervention to learn from their experiences. All meetings were recorded and transcribed verbatim.

\section{Data analysis}

The variance in the difference between each primary or coprimary outcome measure between groups was

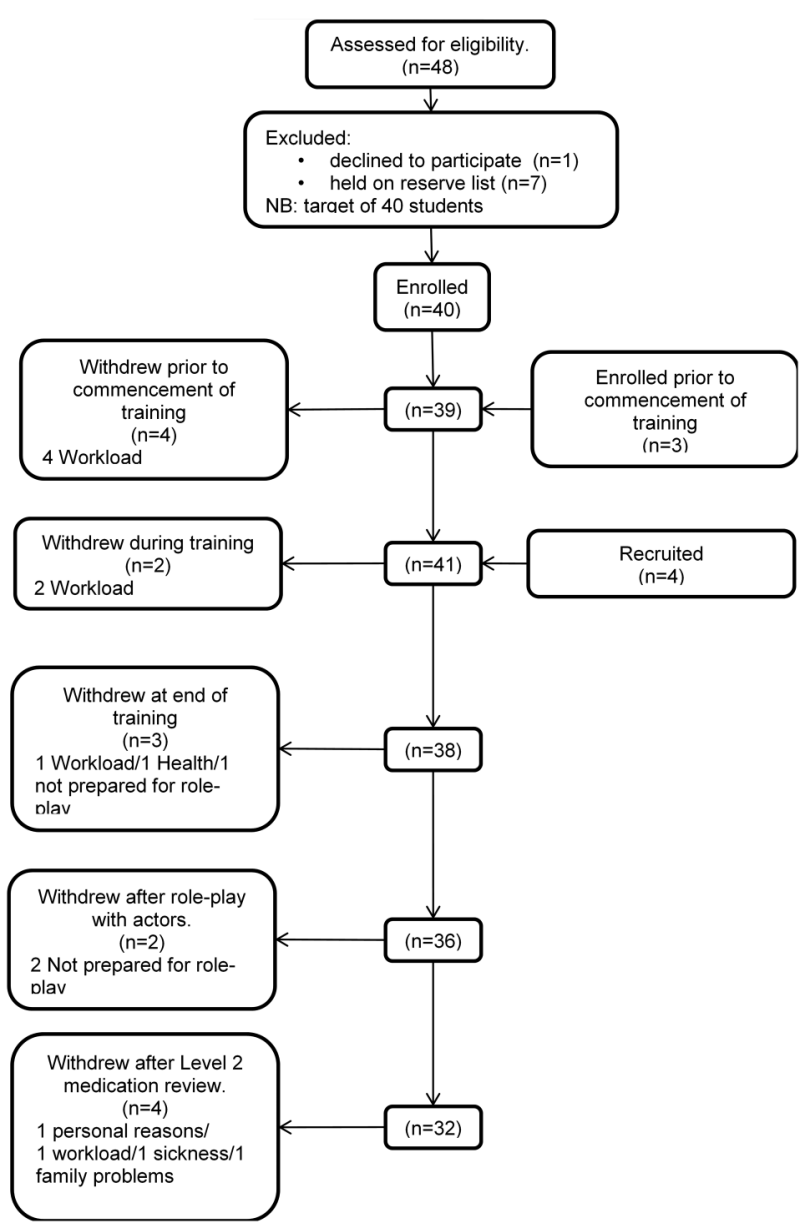

Figure 2 Consort diagram for student participants. 
undertaken on an intention-to-treat basis using independent $\mathrm{t}$ test and Mann-Whitney $\mathrm{U}$ test. The patient recruitment rate and the medicine-related consultation uptake rate were both determined. SPSS V.22 was used for analysis.

\section{Stakeholder meeting analysis}

Simple content analysis which proceeded to identify all themes, as recognised by the researcher, was undertaken for development meetings with the main learning points recorded for action as appropriate. Review meeting analysis followed the general principles of the framework approach. ${ }^{36}$ There was no independent analysis of the data. Nvivo 10 was used to facilitate analysis.

\section{Health economics analysis}

As a pilot study we report completion rates for resource use items and the EQ-5D. Additionally, unit $\operatorname{costs}^{37}$ were extracted in order to enable the cost of the intervention to be estimated.

\section{RESULTS}

All five medical practices which responded to recruitment requests were consented to join the study.

Figure 1 summarises the patient recruitment process which achieved a $16.8 \%$ consent rate. Recruitment rates within the five medical practices were $17.2 \%, 19.6 \%$,
$20.1 \%, 18.5 \%$ and $9.4 \%$. The research team received a number of contacts from patients who had been approached by the medical practice with a $9.4 \%$ response rate to complain that they had received recruitment letters without stamps. The first two practices recruited in time to enable students to complete medication reviews before Christmas 2011. The other three practices recruited later resulting in student-led medication reviews in one practice being undertaken in March 2012. Of the 67 patients randomised to intervention, $91 \%$ remained in the study prior to the student-led medication review with $100 \%$ of those agreeing to an appointment with a student for a consultation. Of these, three $(4.9 \%)$ failed to attend the consultation.

Figure 2 provides a summary of the flow of students at each stage of the study. Of the 47 students who volunteered and completed a consent form, $12.75 \%$ were male. The first 40 students volunteering were recruited with the remaining seven forming the reserve list used if recruited students left the study. Patient consultations were undertaken by 32 of the $47(68 \%)$; however, of these six only undertook one consultation due to patient numbers. Mean (SD) examination scores at end of year three (at recruitment) for participating and nonparticipating students were $62.80 \quad(7.91)$ and 58.91 (7.98), respectively. Academic performance of participating students was significantly better than non-

Table 1 Comparison of patient demographics at baseline

\begin{tabular}{|c|c|c|c|c|}
\hline Characteristic & Measure & $\begin{array}{l}\text { Usual range or } \\
\text { ideal figure }\end{array}$ & $\begin{array}{l}\text { Intervention } \\
\text { patients }(n=67)\end{array}$ & $\begin{array}{l}\text { Control patients } \\
(n=66)\end{array}$ \\
\hline Age & Mean (SD) & NA & $69.18(10.46)$ & $68.31(9.46)$ \\
\hline Male & Number (\%)t & NA & $45(68 \%)$ & $38(58.5 \%)$ \\
\hline $\mathrm{HbA} 1 \mathrm{c} \mathrm{mmol} / \mathrm{mol}$ & Mean (SD) & 48 & $56.81(11.12)$ & $59.71(13.92)$ \\
\hline Total cholesterol mmol/L & Mean (SD) & $<4.0$ & $4.14(0.99)$ & $4.19(0.91)$ \\
\hline \multicolumn{5}{|l|}{ Blood pressure $\mathrm{mm} \mathrm{Hg}$} \\
\hline Systolic & Mean (SD) & 140 & $132.48(11.98)$ & $131.65(10.90)$ \\
\hline Diastolic & Mean (SD) & 80 & $73.22(8.15)$ & $72.13(9.54)$ \\
\hline \multirow[t]{2}{*}{ Euroqol VAS scale } & Median (IQ) & NA & $(n=45)$ & $(n=48)$ \\
\hline & & & $80(70,90)$ & $80(70,90)$ \\
\hline \multirow[t]{2}{*}{ EQ-5D-5L } & & & $(n=43)$ & $(n=48)$ \\
\hline & Mean (SD) & NA & $0.766(0.168)$ & $0.736(0.184)$ \\
\hline \multicolumn{3}{|l|}{ SIMS } & $(n=43)$ & $(n=47)$ \\
\hline Total & Median (IQ) & 17 & $12(7,17)$ & $12(8,15.5)$ \\
\hline Action and use & Median (IQ) & 9 & $7(4.75,9)$ & $7(5,9)$ \\
\hline Potential problems & Median (IQ) & 8 & $5.5(2.25,8)$ & $5(2,8)$ \\
\hline \multicolumn{3}{|l|}{$\mathrm{BMQ}$} & $(n=43)$ & $(n=47)$ \\
\hline Necessity & Median (IQ) & 5 & $18(16,21)$ & $19(17,21)$ \\
\hline Concerns & Median (IQ) & 5 & $11.5(10,14)$ & $13(10,16)$ \\
\hline \multirow{2}{*}{ MARS } & & & $(n=43)$ & $(n=47)$ \\
\hline & Median (IQ) & 25 & $24(23,24)$ & $24(23,24)$ \\
\hline \multicolumn{3}{|l|}{ DTSQ } & $(n=45)$ & $(n=48)$ \\
\hline Treatment satisfaction & Median (IQ) & 36 & $30(26,35)$ & $31(26,34)$ \\
\hline Problem-hyperglycaemia & Median (IQ) & 0 & $1(0,3)$ & $2(0,3)$ \\
\hline Problem-hypoglycaemia & Median (IQ)s & 0 & $0(0,1)$ & $0(0,3)$ \\
\hline Using a medicine compliance aid (MCA) & Number (\%) & NA & $44(47.7 \%)$ & $48(43.8 \%)$ \\
\hline
\end{tabular}


participating students at the point of recruitment $(p<0.05$, independent samples $t$ test $)$.

Table 1 presents baseline, demographic, clinical and questionnaire data for control and intervention patients. The data indicate that randomisation resulted in reasonably comparable groups, although the wide SD demonstrates considerable numbers of patients in each group were failing to achieve clinical targets.

Table 2 presents 6 months postintervention data including clinical data and results of patient-completed questionnaires. Questionnaire responses were received from $94(70.7 \%)$ of the 133 patients with nonrespondents and omission of responses to individual questions being comparable across the two groups. Significant differences between intervention and control groups were only observed for change in quality of life and some elements of SIMS.

Figure 3 illustrates a comparison of the SIMS questionnaire responses for intervention and control patients at follow-up (6 months postintervention). It demonstrates that patients in the intervention group were significantly more satisfied with five parameters (one action and usage, four concerns) out of the 17 questions.

Control $\mathrm{n}=34$ Intervention $\mathrm{n}=36$.

Twenty-five $(55.5 \%)$ patients who had met a student for a level 3 medication review and answering this question agreed or strongly agreed that they were far more likely to speak to a pharmacist about their medicines or their health following the medication review, while 11 $(24.5 \%)$ were unsure.

It was calculated that for a full randomised controlled trial (RCT) to demonstrate an effect on HbAlc, 159 patients would be required in each arm of control and intervention to demonstrate $80 \%$ power with 214 patients per group to demonstrate a $90 \%$ power. Data utilised for sample size analysis are presented in table 3 .

\section{Health economics analysis}

The mean per participant cost of the intervention was $£ 164.41$; table 4 provides a breakdown of the component parts. We used different versions of the EQ-5D (the fivelevel version ${ }^{38}$ at baseline and the three-level ${ }^{39}$ at follow-up)

Table 2 Comparison of patient outcomes post-intervention

\begin{tabular}{|c|c|c|c|c|c|}
\hline Characteristic & Measure & $\begin{array}{l}\text { Intervention } \\
(\mathrm{n}=67)\end{array}$ & Control $(n=66)$ & $\begin{array}{l}p \\
\text { Value }\end{array}$ & $\begin{array}{l}\text { Mean }(95 \% \mathrm{Cl}) \text { difference OR } \\
\text { Median difference }\end{array}$ \\
\hline \multirow[t]{2}{*}{$\mathrm{HbA} 1 \mathrm{c} \mathrm{mmol} / \mathrm{mol}$} & Number (\%) & $59(88.1)$ & $59(89.4)$ & & \\
\hline & Mean (SD) & $56.32(11.5)$ & 59.68 (13.2) & $0.14 \#$ & $-3.36(-7.781$ to 1.11$)$ \\
\hline \multirow[t]{2}{*}{ Total cholesterol mmol/L } & Number (\%) & $61(91.0)$ & $53(80.3)$ & & \\
\hline & Mean (SD) & $4.22(1.0)$ & $4.01(0.8)$ & $0.47 \#$ & $0.13(-0.23$ to 0.5$)$ \\
\hline Blood pressure $\mathrm{mm} \mathrm{Hg}$ & Number (\%) & $61(91)$ & 60 (90.9) & & \\
\hline Systolic & Mean (SD) & $132.26(12.9)$ & $127.98(11.9)$ & $0.06 \#$ & $4.35(-0.15$ to 8.84$)$ \\
\hline Diastolic & Mean (SD) & $73.38(6.8)$ & $70.97(9.5)$ & $0.11 \#$ & $2.41(-0.52$ to 5.34$)$ \\
\hline \multirow[t]{2}{*}{ Euroqol VAS } & Number (\%) & $51(76.1)$ & $48(72.7)$ & & \\
\hline & Median (IQ) & $80(70,85)$ & $72.5(61.3,85)$ & $0.182^{*}$ & 7.75 \\
\hline \multirow[t]{2}{*}{ Change from baseline } & Number (\%) & $37(55.2)$ & $40(60.6)$ & & \\
\hline & Mean (SD) & $+2.00(8.73)$ & $-6.24(18.28)$ & $0.015 \#$ & 8.24 (1.65 to 14.8$)$ \\
\hline \multirow[t]{2}{*}{ EQ-5D-3L } & Number (\%) & $51(76)$ & $46(69.7)$ & & \\
\hline & Mean (SD) & $0.768(0.224)$ & $0.736(0.233)$ & 0.49 & $0.031(-0.06$ to 0.123$)$ \\
\hline \multirow[t]{2}{*}{ Change from baseline } & Number (\%) & $35(52.2)$ & $38(57.6)$ & & \\
\hline & Mean (SD) & $0.048(0.133)$ & $-0.003(0.134)$ & $0.103 \#$ & $0.052(-0.011$ to 0.114$)$ \\
\hline SIMS & Number (\%) & $50(74.6)$ & $47(71.2)$ & & \\
\hline Total & Median (IQ) & $14(9.2,17)$ & $10(6,15)$ & $0.073^{\star}$ & 4 \\
\hline Action and usage & Median(IQ) & $8(7,9)$ & $8(6,9)$ & $0.078^{*}$ & 0 \\
\hline Potential problems & Median (IQ) & $3(5,8)$ & $2(3.5,7.7)$ & $0.037^{\star}$ & 1 \\
\hline $\mathrm{BMQ}$ & Number (\%) & $48(71.6)$ & 49 (74.2) & & \\
\hline Necessity & Median (IQ) & $20(18,22.5)$ & $20(19,22)$ & $0.925^{\star}$ & 0 \\
\hline Concerns & Median (IQ) & $14(12,16)$ & $14(12,15)$ & $0.825^{\star}$ & 0 \\
\hline \multirow[t]{2}{*}{ MARS } & Number (\%) & $50(74.6)$ & $48(72.7)$ & & \\
\hline & Median (IQ) & $24(23,2)$ & $24(23,2)$ & $0.843^{\star}$ & 0 \\
\hline DTSQ & Number (\%) & $49(73.1)$ & $48(72.7)$ & & \\
\hline Treatment satisfaction & Median (IQ) & $32(26.5,35)$ & $30.5(27.7,33.2)$ & $0.413^{\star}$ & 1.5 \\
\hline Problem-hyperglycaemia & Median (IQ) & $1(0,3)$ & $1(0,2)$ & $0.360^{\star}$ & 0 \\
\hline Problem-hypoglycaemia & Median (IQ) & $1(0,1)$ & $0(0,2)$ & $0.929^{\star}$ & 1 \\
\hline Using a medicine & Number (\%) & $50(74.6)$ & $46(69.7)$ & & \\
\hline compliance aid (MCA) & Number (\%) & $23(46.0)$ & $25(54.3)$ & $0.540 \$$ & \\
\hline
\end{tabular}




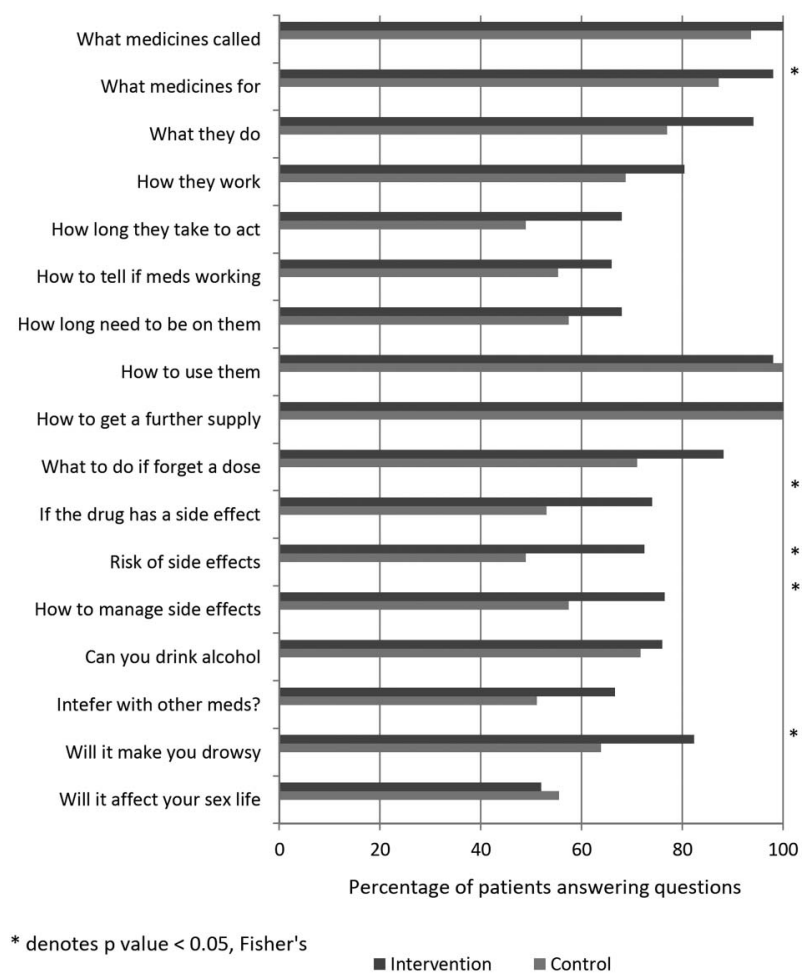

Figure 3 Provides a comparison of the satisfaction with information about medicines (SIMS) questionnaire responses for intervention and control patients at follow-up (6-month postintervention). It demonstrates that patients in the intervention group were significantly more satisfied with five parameters (one action and usage, four concerns) of the 17 questions (control $n=34$; intervention $n=36$ ).

to assess whether completion rates differed according to the number of levels. The response rates were slightly higher for the EQ-5D-3 L and the mean change in EQ-5D score was slightly higher for the intervention arm (see tables 1 and 2). Complete cost and effect data were available for 72 participants ( $54.1 \%$ of the sample).

\section{Stakeholder meetings}

All stakeholder groups supported the testing of the idea. There was agreement that student-led consultations should take place at the medical practice of each patient rather than at the university, should not be time-limited and should be supervised. Postintervention stakeholder groups agreed that the experience had been generally positive, had provided both student and patient benefit and raised awareness of the role of pharmacists.

Table 4 provides a summary of the main points learned from the stakeholder meetings before and after intervention where opinions did not concur across groups.

Table 5 presents identified intervention costs. It can be seen that there are significant fixed costs associated with setting up the service: the mean cost per participant is relatively small.

\section{DISCUSSION}

This pilot study has demonstrated the acceptability and practicality of pharmacy students providing full medication review to patients with type 2 diabetes under supervision. All stakeholder groups displayed support for the concept, with patients also displaying a willingness to participate in a subsequent RCT. Medical practices were purposively selected, and no problems were experienced with patient recruitment, though recruitment rates were relatively low $(17 \%)$ and may display a better response rate without postal issues experienced at one medical practice. Nevertheless, future recruitment for a full RCT would be possible and may display a better response without postal issues experienced at one medical practice. Importantly, there was also a very low patient dropout rate $(<10 \%)$. The logistics of patients having to attend an additional clinic within the intervention group resulted in the loss of patients due to illness and bereavement which were unavoidable losses to the study and two due to forgetting to attend. A longer period to allow for rebooking and reminders closer to the time of the appointment may have prevented these drop-outs. A longer time period to allow for rebooking and reminders closer to the appointment may have helped but would increase the costs. Potential patient benefit was also identified within some of the outcome measures. The results, therefore, provide evidence that within an RCT, sufficient patients could be expected to agree to attend for a medication-related consultation.

As this was a pilot study, and had small participant numbers we did not expect to demonstrate significant effects in our outcome measures. Students were volunteers and may not represent a full population of undergraduate pharmacy students. All participating medical practices were requested to start recruitment at the same

Table 3 Data used to calculate sample size

\begin{tabular}{llllll}
\hline $\begin{array}{l}\text { Output } \\
\text { measure }\end{array}$ & $\begin{array}{l}\text { Standard error of } \\
\text { mean difference \# }\end{array}$ & $\begin{array}{l}\text { Standard deviation } \\
\text { of mean difference }\end{array}$ & $\begin{array}{l}\text { Clinically } \\
\text { important } \\
\text { difference }\end{array}$ & $\begin{array}{l}\text { Unit of } \\
\text { clinical } \\
\text { measure }\end{array}$ & $\begin{array}{l}\text { Number of patients } \\
\text { required in each } \\
\text { group }\end{array}$ \\
\hline HbA1c & 2.28 & 17.5 & 5.5 & $\mathrm{mmol} / \mathrm{mol}$ & 159 \\
$\begin{array}{l}\text { Systolic blood } \\
\text { pressure }\end{array}$ & 2.27 & 12.47 & 3.3 & $\mathrm{~mm} \mathrm{Hg}$ & 224 \\
\hline
\end{tabular}

Patients were included in the intention to treat analysis even if they did not complete questionnaires.

$\mathrm{HbA1c}$, glycated haemoglobin. 
Table 4 Main points learned from stakeholder meetings

\begin{tabular}{|c|c|c|}
\hline Location & Patients & Students \\
\hline Preintervention & $\begin{array}{l}\text { Care plan or protocol for use during consultation } \\
\text { Current unmet information need } \\
\text { Ensure paperwork is easily comprehensible } \\
\text { Ensure students are confident } \\
\text { Ensure preparative training } \\
\text { Supervision of student essential } \\
\text { Students must admit knowledge gaps }\end{array}$ & $\begin{array}{l}\text { Transport should be provided } \\
\text { Group feedback on their performance where } \\
\text { possible }\end{array}$ \\
\hline Postintervention & $\begin{array}{l}\text { Real-life teaching required } \\
\text { Willingness to participate in the future } \\
\text { Recruitment-avoid Christmas and mail best method } \\
\text { Confirmed GP practice best location } \\
\text { Praise (not universal) for students' consultation skills } \\
\text { Request use of email within consent and utilise for } \\
\text { appointments and reminders where agreed }\end{array}$ & $\begin{array}{l}\text { Preparative training-some elements and timing } \\
\text { criticised. Role play most effective } \\
\text { Supervisor feedback useful } \\
\text { Level } 2 \text { medication effective preparation for } \\
\text { consultation } \\
\text { Wanted consultations with more patients } \\
\text { Difficulties completing study outside course } \\
\text { Educational benefit obtained } \\
\text { Preferred to Objective Structured Clinical } \\
\text { Examinations (OSCEs) or role play }\end{array}$ \\
\hline Location & Primary care pharmacists & Medical practice staff \\
\hline Preintervention & $\begin{array}{l}\text { Care plan or protocol for use during consultation } \\
\text { Ensure preparative training } \\
\text { Students access medical record prior to consultation }\end{array}$ & $\begin{array}{l}\text { Care plan or protocol for use during consultation } \\
\text { Ensure preparative training } \\
\text { Students access medical record prior to } \\
\text { consultation } \\
\text { Ensure students do not contradict nurse advice }\end{array}$ \\
\hline Postintervention & $\begin{array}{l}\text { Role play good-in 'protected' environment } \\
\text { Supervisor feedback useful } \\
\text { Enjoyed participation } \\
\text { Improved their own continuing professional } \\
\text { development (CPD) } \\
\text { Confirmed that GP practice best location } \\
\text { Feedback after each consultation improved } \\
\text { performance }\end{array}$ & $\begin{array}{l}\text { Consultation must be recorded in patient's records } \\
\text { Need protected time for students to feedback } \\
\text { recommendations }\end{array}$ \\
\hline
\end{tabular}

time; however, results demonstrate patient recruitment proceeding over a period of greater than 4 months, resulting in logistical issues within the project. Ethical reasons required recruitment to be initiated via the medical practices, but results suggest that closer communication and support may be required between the researcher and medical practices to facilitate earlier recruitment. Written appointment information may aid patient attendance and prevent the small number of patients failing to attend due to forgetfulness. The large number of statistical tests carried out, increases the likelihood of false positives. Conversely as a pilot and feasibility study with limited sample size there is an increased likelihood of false negatives.

While student willingness to participate was high, pressures of concurrent timetabled course work and a lack of confidence in ability to perform the consultation resulted in significant drop out during the progress of the study. Integration of the service into the curriculum did not result in drop out from similar non-UK studies. ${ }^{18} 19$ Participating students were volunteers and, therefore, self-selecting. Given that they were, on average, academically superior when compared to non- participating students, they would potentially have performed better than non-participants during a student-led consultation. Most studies do not mention this effect and any future study utilising volunteer students should recognise and allow for it. ${ }^{18} 40-43$ The educational element of this study was not considered within this paper as this will form the focus of a future submission. The quality of medicines information given to patients affects individual's perception of whether it has met their needs and if they are satisfied with the information provided. ${ }^{32}$ It is reasonable to speculate that repetition of information over a period of years to patients with a long-term condition would have resulted in a greater understanding of and, therefore, satisfaction with information about their medicines. This may have reduced the ability to improve scores for many of the individual questions. While higher scores for SIMS is theoretically a predictor for better adherence (MARS) ${ }^{32}$ no improvement in adherence was observed. The relatively high proportion of patients who reported using medication compliance aids prior to the intervention might have reduced the potential for the intervention to further improve adherence. Adherence, beliefs about 
Table 5 Resource utilisation costs

\begin{tabular}{|c|c|c|c|}
\hline Component part & Resources costed (unit cost), participant costing & $\begin{array}{l}\text { Total } \\
\text { cost }(£)\end{array}$ & $\begin{array}{l}\text { Mean cost as } £ \\
\text { per participant }\end{array}$ \\
\hline Development of training plan & $\begin{array}{l}1 \text { h meeting for } 4 \text { people ( } 3 \text { pharmacists @ } £ 50 \text { per } \\
\text { hour*; } 1 \text { RA @£25 per hour }+ \text { ) }\end{array}$ & 175.00 & 2.61 \\
\hline $\begin{array}{l}\text { Development of background } \\
\text { material }\end{array}$ & $\begin{array}{l}\text { Podcasts on diabetes and cardiovascular and } \\
\text { communication skills. } 1.5 \mathrm{~h} \text { of pharmacist time @ } £ 50 \\
\text { per hour*; }\end{array}$ & 75.00 & 1.12 \\
\hline IT workshop & $\begin{array}{l}1 \text { day preparation (RA @ } £ 25 \text { per hourt); IT Dept. costs } \\
\text { (room and trainer for } 4^{\star} 0.5 \text { day sessions—£600 flat fee); } \\
\text { supervision and assistance with training ( } 2 \text { days of } \\
\text { pharmacist time @£50 per hour*) }\end{array}$ & 887.50 & 13.25 \\
\hline Care planning workshop & $\begin{array}{l}\text { Preparation (1 h RA @£25 per hourt and } 1 \text { h } \\
\text { pharmacist @ £50 per hour); delivery ( } 3 \text { h RA time @ } \\
£ 25 \text { per hour† and } 3 \text { h pharmacist time @ } £ 50 \text { per hour) }\end{array}$ & 300.00 & 4.48 \\
\hline $\begin{array}{l}\text { Communication/consultation } \\
\text { skills with motivational } \\
\text { interviewing }\end{array}$ & $\begin{array}{l}\text { Preparation ( } 2 \text { h pharmacist time @ } £ 50 \text { per hour); } \\
\text { delivery ( } 3 \text { h RA time @£25 per hourt and } 3 \text { h } \\
\text { pharmacist time @ } £ 50 \text { per hour) }\end{array}$ & 325.00 & 4.85 \\
\hline Role play workshop & $\begin{array}{l}\text { Preparation ( } 9.5 \text { h RA time @£25 per hour } \text { and } 3 \text { days } \\
\text { of pharmacist time @£50 per hour) Per session: } 2 \text { h of } \\
\text { consultation/MR practice ( } 2 \text { h RA time @£25 per hour† } \\
\text { and } 2 \text { h pharmacist time @ } £ 50 \text { per hour) and } 1 \text { h of GP } \\
\text { feedback ( } 1 \text { h RA time @£ } 25 \text { per hourt and } 1 \text { h GP time } \\
@ £ 118 \text { per hour). } 7 \text { sessions ( } 6 \text { students per session). }\end{array}$ & 3238.50 & 48.34 \\
\hline Level 2 review & $\begin{array}{l}\text { Based in general practice, look at medical records and } \\
\text { create care plans. Per session: } 3 \text { hours of pharmacist } \\
\text { time (@£50 per hour*). Specialist nurse attended for the } \\
\text { last hour ( @£52 per hour). } 13 \text { sessions held ( } 3 \text { students } \\
\text { per group) }\end{array}$ & 2626.00 & 39.19 \\
\hline Level 3 review & $\begin{array}{l}1 \mathrm{~h} \text { per patient at general practice (pharmacist @ } £ 50 \\
\left.\text { per hour }{ }^{\star}\right) . \text { Specialist nurse attended for } 15 \text { min ( @£52 } \\
\text { per hour). Held with } 54 \text { patients }\end{array}$ & 3402.00 & 50.78 \\
\hline
\end{tabular}

medication, satisfaction with diabetes treatment and quality of life all displayed a change in the direction which favours the intervention, all of which support a full study going ahead. No evidence is available to definitively explain the change in blood pressure seen in the control group and reasons for this would only be speculative, but it may simply have been a chance finding. It may be more appropriate to focus the intervention on those patients with the greatest HbAlc or the lowest reported satisfaction with information or adherence, however this may affect the recruitment rate and would require careful consideration prior to implementation in a full RCT if using the results from this study for it basis.

Results demonstrate that HbAlc would appear to be a sensible primary outcome measure for a future study. A sample size of 214 patients per group (428 in total) would be required to demonstrate a $90 \%$ power. This would equate to 107 students (two patient consultations per student), which is achievable within a full RCT undertaken over more than one school of pharmacy. However, recent National Institute for Health and Care Excellence (NICE) guidance recommends the utilisation of a cardiac risk measure (QRisk2) ${ }^{44-46}$ which represents a compilation of clinical data. Insufficient data is available to calculate a sample size for QRisk2, therefore, the pragmatic decision would be to utilise a primary outcome measure of HbA1c with QRisk2 possibly utilised as a secondary outcome measure.

Implementation of student activity described within this study is in line with current government agenda for pharmacy education. ${ }^{47}$ Evidence does not exist in the UK to support the training of undergraduate pharmacy students when undertaking activities with real patients, although examples exist outside the UK. ${ }^{18}{ }^{19} 42$ This study does not provide definitive evidence for this, but does provide support for a future definitive RCT to test this hypothesis.

With a known patient recruitment rate and low dropout rate this demonstrates that if utilising the same protocol for a future RCT, not only can sufficient numbers of patients be expected to be recruited and retained. Medical practices were chosen because they all used the same software system for electronic medical records, as this would facilitate student training, however, utilising additional systems would increase the number of general practitioner practices available for recruitment. 
Changes may be warranted to patient selection criteria, as recruitment of patients who are not yet clinically stabilised may be more receptive to information regarding their medicines. NICE CG66 ${ }^{44}$ recommends a blood pressure target level of $<140 / 80 \mathrm{~mm} \mathrm{Hg}$ for most people with type 2 diabetes, and $<130 / 80 \mathrm{~mm} \mathrm{Hg}$ for those at more particular risk. The latter group includes people with raised albumin excretion rate (microalbuminuria or worse), estimated glomerular filtration rate $<60 \mathrm{~mL} /$ $\min / 1.73 \mathrm{~m}^{2}$, those with retinopathy, and those with prior stroke or transient ischaemic attack. Data to enable such differentiation was not obtained within the pilot study and should be included in the design of a future definitive RCT. Provision of opportunities for students to undertake more than two consultations in future studies may demonstrate further student and patient benefit. Results provide evidence that within an RCT, sufficient patients could be expected to agree to attend for a medication-related consultation. Written appointment information may aid patient attendance and prevent the small number of patients failing to attend due to forgetfulness. Where acceptable to participants, email appointments and reminders for consultations may be effective. This pilot study confirms that the data required for evaluation of health economics is possible in a RCT. To address the rate of availability of cost and effect data, in any future study we would make every effort to ensure that baseline measures are completed prior to randomisation. The design of a definitive trial should ensure that medical practitioners receive feedback from the students to potentially increase the effectiveness of the intervention. The results from this study display good generalisation, as recruitment and the intervention followed existing scenarios where possible, however student academic ability may affect interpretation. Results support a future RCT as the intervention appeared to have the potential to improve blood glucose sugar control, quality of life and medicine information and these findings need more formal testing.

\author{
Author affiliations \\ ${ }^{1}$ School of Pharmacy, University of East Anglia, Norwich, Research Park, \\ Norwich, UK \\ ${ }^{2}$ Norwich Medical School and Norwich Clinical Trials Unit, University of East \\ Anglia, Norwich Research Park, Norwich, UK \\ ${ }^{3}$ School of Pharmacy, University of Lincoln, Lincoln, UK \\ ${ }^{4}$ Norwich Medical School, University of East Anglia, Norwich Research Park, \\ Norwich, UK \\ ${ }^{5}$ School of Education \& Lifelong Learning, University of East Anglia, Norwich \\ Research Park, Norwich, UK
}

Acknowledgements Thanks are due to the patients, medical practices and their staff, and pharmacy students who took part in the study. Thanks are due to the academic staff at the UEA for guidance and practical assistance, the Norwich Clinical Trials Unit and also to practice-based pharmacists who assisted with supervision.

Contributors DJW conceived the study and led the writing of the proposal for funding, provided day to day supervision of study conduct, analysis and interpretation of data, and co-led the writing of the paper, including revisions and final draft. DJW, RPA, DB, RH, AH, NN were coinvestigators, contributing to writing of the proposal, oversight of the study conduct, data analysis and interpretation, drafting of the paper and approved the final version. GB undertook the analysis and interpretation of the health economic data and led the drafting of the health economic components of this article. LS provided oversight for the statistical analyses. PFG, DJW, DB, RPA provided the expertise on the design and delivery of the pharmacist training. RPA was responsible for daily study conduct and coordination, acquisition of the data, analysis, producing tables and figures and interpretation of data and co-led with DJW the drafting of this paper. DJW approved the final version. All authors participated in a critical revision of the manuscript and have approved the final version.

Funding This work was supported by the National Institute for Health Research (NIHR) under Research for Patient Benefit grant no. PB-PG-0909-19198. The views expressed are those of the authors and not necessarily those of the NHS, NIHR or the Department of Health.

Competing interests DJW declared a consultancy with Health Education England to determine the costs associated with clinically training pharmacists.

\section{Patient consent Obtained.}

Ethics approval Ethical approval was obtained from Cambridge three ethics committee in January 2010 and NHS management permission was obtained from NHS South Norfolk CCG (formerly NHS Norfolk and Waveney PCT) prior to start of the study. Ethics ref no. 10/H0306/77. University of East Anglia ethical approval was obtained to permit collection of student examination results.

Provenance and peer review Not commissioned; externally peer reviewed.

Data sharing statement No additional data are available.

Open Access This is an Open Access article distributed in accordance with the terms of the Creative Commons Attribution (CC BY 4.0) license, which permits others to distribute, remix, adapt and build upon this work, for commercial use, provided the original work is properly cited. See: http:// creativecommons.org/licenses/by/4.0/

\section{REFERENCES}

1. Patient Safety Observatory. Safety in doses: medication safety incidents in the NHS. Secondary Safety in doses: medication safety incidents in the NHS 2007. http://www.nrls.npsa.nhs.uk/ patient-safety-data/

2. Garfield S, Barber N, Walley $\mathrm{P}$, et al. Quality of medication use in primary care--mapping the problem, working to a solution: a systematic review of the literature. BMC Med 2009;7:50.

3. Winstein A, Sauer B, Hepler C, et al. Preventable drug-related hospital admissions. Ann Pharmacother 2002;36: 1238-48.

4. Barber N, Parsons J, Clifford S, et al. Patients' problems with new medication for chronic conditions. Qual Saf Health Care 2004;13:172-5. http://qualitysafety.bmj.com/content/13/3/172.full.pdf +html?sid=eab8a148-1816-4383-969a-248bd1e754c8 (accessed 1 Dec 2013)

5. Taskforce on Medicines Partnership National Collaborative Medicines Management Services Programme. Room for review. A guide to medication review: the agenda for patients, practitioners and managers. London: Medicines Partnership, 2002

6. Zermansky AG, Petty DR, Raynor DK, et al. Clinical medication review by a pharmacist of patients on repeat prescriptions in general practice: a randomised controlled trial. Health Technol Assess 2002;6:1-86. http://www.hta.ac.uk/pdfexecs/summ620.pdf (accessed 12 Apr 2011).

7. Holland R, Lenaghan E, Harvey I, et al. Does home based medication review keep older people out of hospital? The HOMER randomised controlled trial. BMJ 2005;330:293.

8. Salter C, Holland R, Harvey I, et al. "I haven't even phoned my doctor yet." The advice giving role of the pharmacist during consultations for medication review with patients aged 80 or more: qualitative discourse analysis. BMJ 2007;334:1101.

9. Salter C. Compliance and concordance during domiciliary medication review involving pharmacists and older people. Sociol Health IIIn 2010;32:21-36.

10. Kinmonth AL, Woodcock A, Griffin S, et al. Randomised controlled trial of patient centred care of diabetes in general practice: impact on current wellbeing and future disease risk. BMJ 1998;317:1202-8. 
11. National Institute for Health and Clinical Excellence. Medicines adherence Involving patients in decisions about prescribed medicines and supporting adherence. NICE clinical guideline 76. Secondary Medicines adherence Involving patients in decisions about prescribed medicines and supporting adherence. NICE clinical guideline 76 2009. http://guidance.nice.org.uk/CG76/NICEGuidance/pdf/English

12. Kurtz S, Silverman J. The Calgary-Cambridge referenced observation guides: an aid to defining the curriculum and organising the teaching in communication training programmes. Med Educ 1996;30:83-9.

13. Abdel-Tawab R, Higman-James D, Fichtinger A, et al. Development and validation of the Medication-Related Consultation Framework (MRCF). Patient Educ Couns 2011;83:451-7.

14. Wright $D$, Loftus $D$, Christou M, et al. Healthcare professional education \& training: how does pharmacy in Great Britain compare? Norwich: Royal Pharmaceutical Society of Great Britain, 2006.

15. Howe A, Anderson J. Involving patients in medical education. BMJ 2003;327:326-8.

16. King's College London. Free dental care by undergraduate students at Guy's and St Thomas' Hospitals. Secondary Free dental care by undergraduate students at Guy's and St Thomas' Hospitals 2013. http://www.kcl.ac.uk/dentistry/patient/index.aspx

17. School of Optometry \& Vision Sciences Cardiff University. Eye examinations. Secondary eye examinations 2013. http://www.cardiff. ac.uk/optom/eyeclinic/eyeexaminations/index.html

18. Boyatzis M, Batty K. Domiciliary medication reviews by fourth year pharmacy students in Western Australia international journal of pharmacy practice. 2004;12:73-81.

19. Janson S, Cooke M, McGrath KW, et al. Improving chronic care of type 2 diabetes using teams of interprofessional learners. Acad Med 2009;84:1540-8.

20. McCollum M, Nuffer W, Ellis S, et al. Physician acceptance of pharmacotherapy recomendations made by pharmacy students in a rural pharmacy-based diabetes care and education clinic. Am J Pharm Educ 2009;73:24.

21. Diabetes UK. NHS spending on diabetes to reach 16.9 billion by 2035. Secondary NHS spending on diabetes to reach 16.9 billion by 2035 2013. http://www.diabetes.org.uk/About_us/News_Landing_ Page/NHS-spending-on-diabetes-to-reach-169-billion-by-2035/

22. Lowey A, Moore S, Norris $\mathrm{C}$, et al. The cost-effectiveness of pharmacist-led treatment of cardiac risk in patients with type 2 diabetes. Pharm World Sci 2007;29:541-5.

23. McGowan N, Cockburn A, Strachan MW, et al. Initial and sustained cardiovascular risk reduction in a pharmacist-led diabetes cardiovascular risk clinic. Br J Diab Vasc Dis 2008;8:34-8.

24. Nau D, Ponte C. Effects of a community pharmacist-based diabetes patient-management program on intermediate clinical outcome measures. J Managed Care Pharmacy 2002;8:48-53.

25. Wermeille J, Bennie M, Brown I, et al. Pharmaceutical care model for patients with type 2 diabetes: integration of the community pharmacist into the diabetes team-a pilot study. Pharm World Sci 2004;26:18-25.

26. No authors listed]. Tight blood pressure control and risk of macrovascular and microvascular complications in type 2 diabetes: UKPDS 38. U.K. Prospective Diabetes Study Group. BMJ 1998;317:703-13.

27. The NHS Information Centre. National Diabetes Audit: Executive Summary 2009-10. http://www.hscic.gov.uk/nda. Date accessed 30/ $10 / 2015$

28. National Institute for Health and Care Excellence. CG66 Type 2 Diabetes: full guideline. Secondary CG66 Type 2 Diabetes: full guideline 2013. http://guidance.nice.org.uk/CG66/Guidance/pdf/English

29. National Institute for Health and Care Excellence. Cardiovascular disease-statins (TA 94). Secondary Cardiovascular diseasestatins (TA 94) Issued Jan 2006. http://www.nice.org.uk/ta094
30. Newcastle Guideline Development and Research Unit, British Hypertension Society, National Collaborating Centre for Chronic Conditions. NICE Clinical Guideline 34, Hypertension: management of hypertension in adults in primary care. National Institute for Health and Clinical Excellence, 2006.

31. Medical Research Council. Complex interventions guidance. Secondary Complex interventions guidance. 2008. http://www.mrc. ac.uk/Utilities/Documentrecord/index.htm?d=MRC004871.

32. Horne R, Hankins M, Jenkins R. The Satisfaction with Information about Medicines Scale (SIMS): a new measurement tool for audit and research. Quality in Health Care 2001;10:135-40.

33. Bowskill R, Clatworthy J, Parham R, et al. Patients' perceptions of information received about medication prescribed for bipolar disorder: Implications for informed choice. J Affect Disorders 2007;100:253-57.

34. Horne R, Weinmann J, Hankins M. The beliefs about medicines questionnaire: the development and evaluation of a new method for assessing the cognitive representation of medicine. Psychol Health 1999;14:1-24

35. Bradley C. The DTSQ. Health Psychology Research, University of London, 2009:1-3.

36. Pope C, Ziebland S, Mays N. Qualitative research in health care: analysing qualitative data. BMJ 2000;320:114-16.

37. Curtis L. Unit costs of health and social care 2012. The University of Kent: Personal Social Services Research Unit, 2012.

38. Herdman M, Gudex C, Lloyd A, et al. Development and preliminary testing of the new five-level version of EQ-5D (EQ-5D-5L). Qual Life Res 2011;20:1727-36.

39. Brooks R. EuroQol: the current state of play. Health Policy 1996;37:53-72.

40. Lundquist LM, Moye PM. Resident physicians' acceptance of pharmacy students' pharmacotherapy recommendations during an ambulatory care advanced pharmacy practice experience. $\mathrm{Am} \mathrm{J}$ Pharm Educ 2009;73:145.

41. Hata M, Klotz R, Sylvies R, et al. Medication therapy management services provided by student pharmacists. Am J Pharm Educ 2012;76:51.

42. O'Neil C, Berdine H. Experiential education at a university-based Wellness center. Am J Pharm Edu 2007;71:49.

43. Nuffer W, McCollum M, Ellis S, et al. Further development of pharmacy student-facilitated diabetes management clinics. Am J Pharm Educ 2012;76:50.

44. National Institute for Health and Care Excellence (NICE). Type 2 diabetes. National guidelines for management in primary and secondary care. CG66. Updated by CG87. Secondary type 2 diabetes. National guidelines for management in primary and secondary care. CG66. Updated by CG87 2002. http://www.nice.org uk/guidance/cg66/resources/cg66-type-2-diabetes-full-guideline2

45. National Institute for Health and Care Excellence (NICE). Type 2 diabetes: The management of type 2 diabetes CG87. Secondary type 2 diabetes: the management of type 2 diabetes CG87 2009. http://www.nice.org.uk/guidance/cg87

46. National Institute for Health and Care Excellence (NICE). Lipid modification: cardiovascular risk assessment and the modification of blood lipids for the primary and secondary prevention of cardiovascular disease CG181. Secondary lipid modification: cardiovascular risk assessment and the modification of blood lipids for the primary and secondary prevention of cardiovascular disease CG181 2014. http://www.nice.org.uk/guidance/cg181

47. Medical Education England. Modernising Pharmacy Careers Programme: review of pharmacist undergraduate education and pre-registration training and proposals for reform. Secondary Modernising Pharmacy Careers Programme: review of pharmacist undergraduate education and pre-registration training and proposals for reform. 2011. http://www.mee.nhs.uk 